\section{Crowfoot-Hodgkin, Dorothy Mary}

\author{
H. Fiedler \\ Erfurt, Deutschland
}

Lebensdaten Englische Chemikerin, geboren am 12. Mai 1910 in Kairo, gestorben am 30. Juli 1994 in Shipston-onStour, England. In der Literatur wird sie oft als Dorothy Hodgkin geführt.

Verdienste Crowfoot-Hodgkin studierte am Somerville College Oxford und an der Universität Cambridge unter Leitung des hervorragenden Kristallographen John Desmond Bernal (1901-1971). Im Jahr 1934 kehrte sie als Research Fellow an das Somerville College zurück und wurde 1960 zur Wolfson Research Professorin der Royal Society ernannt. 1964 erhielt sie als dritte Frau den Nobelpreis für Chemie für die Entschlüsselung des Aufbaus von Vitaminen (besonders Vitamin $B_{12}$ ), Steroiden und Proteinen mittels der Röntgenstrukturanalyse der jeweiligen Kristalle. Sie engagierte sich außerdem für soziale Fragen und in der Friedensbewegung und war von 1976-1988 Präsidentin der Pugwash Conference on Science and World Affairs. 1976 erhielt sie als erste Frau die seit 1731 jährlich an Männer vergebene Copley-Medaille der Royal Society.

Nach ersten Studien mit kristallisiertem Pepsin klärte sie zusammen mit Bernal die Raumstruktur von über 100 Steroiden auf und korrigierte die bis dahin akzeptierten WindausWieland-Formeln ( $>$ Windaus, Adolf Otto Reinhold, $>$ Wieland, Heinrich Otto). Sie nutzte (wie Max Ferdinand Perutz, 1914-2002) den isomorphen Ersatz von Anionen oder Kationen zuerst bei der Strukturaufklärung von Cholesteryliodid und Benzylpenicillin (1945, erstmalig die Laktamstruktur festgestellt). Weitere Höhepunkte waren die Strukturbestimmungen von Vitamin $\mathrm{B}_{12}$ (1948, nach 8 Jahren) und > Insulin (1969, nach 34 Jahren Arbeit). Bis zu ihrem Tod war sie trotz jahrzehntelanger chronischer Krankheit stets wissenschaftlich tätig und bildete viele Schüler in Röntgenstrukturanalyse aus.

\section{Literatur}

Glusker JP (1994) Dorothy Crowfoot Hodgkin (1910-1994). Protein Sci $3: 2465-2469$ 